VThf vs Frequency

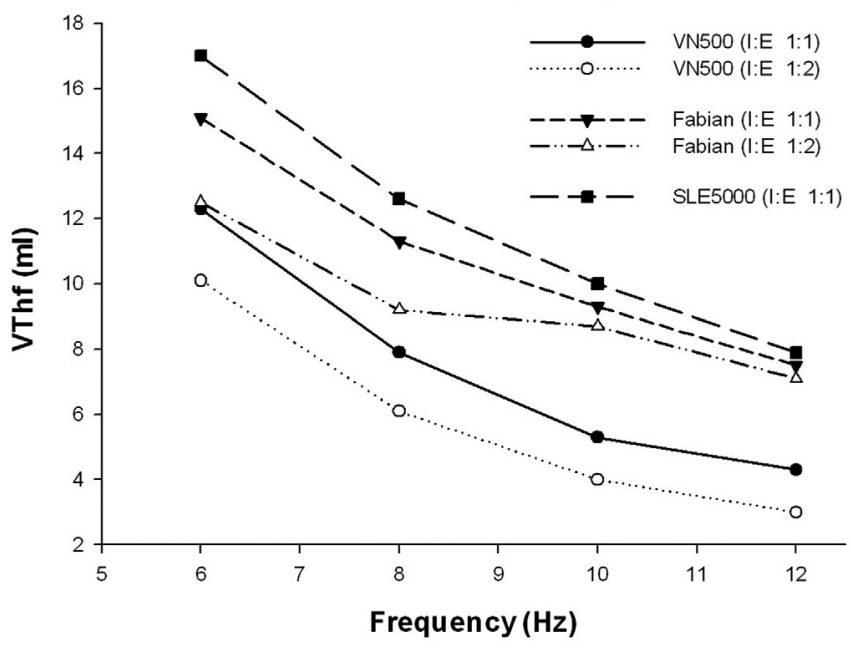

Abstract PS-378 Figure 2

generating the required high frequency oscillation. In HFV, carbon dioxide elimination is directly correlated with VThf. The aim of the current study was to describe the impact of changes in amplitude, frequency and inspiratory-expiratory ratio (I:E) on VThf using different hybrid neonatal ventilators.

Methods Three different hybrid neonatal ventilators were tested: Drager Babylog® VN500, Acutronic Fabian and SLE 5000. Each ventilator was calibrated using a new disposable ventilator circuit with a Drager pneumatic test lung leaving the humidifier dry to standardise all measurements. The VThf measured by the device was recorded after the system stabilised for 3 min. Each experiment was done using $21 \%$ oxygen, $8 \mathrm{~cm} \mathrm{H} \mathrm{H}_{2} \mathrm{O}$ of pressure and repeated 3 times with negligible differences between measurements.

Results In this setting, there is an expected inverse relationship between frequency and achieved VThf in all devices when using maximum amplitude. All three ventilators were more efficient at lower frequencies achieving higher VThf. In the two ventilators that allow I:E modification, the 1:1 ratio achieves higher VThf than 1:2 ratio. This becomes more evident at lower frequencies and higher amplitudes.

Conclusions In tested ventilators the highest impact on VThf was achieved with frequency reduction. When modifiable, an I:E ratio of 1:1 optimises VThf at higher amplitudes. Clinicians need to be aware of these characteristics for optimising ventilation strategy.

\section{PS-379 THE OPTIMAL PREDICTORS OF READINESS FOR EXTUBATION IN LOW BIRTH WEIGHT INFANTS}

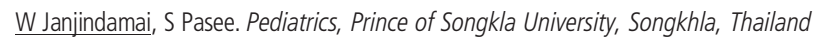

\subsection{6/archdischild-2014-307384.677}

Background and aims Reintubation, following an unsuccessful extubation from mechanical ventilation is traumatic to the infant and the family. However $20-40 \%$ of infants fail extubation and reintubation. The aim of the study was to determine the optimal predictors of readiness for extubation in low birth weight infants during endotracheal tube-continuous positive airway pressure (ETT-CPAP) for three minutes.
Methods A prospective cohort study was undertaken in 51 mechanically ventilated infants who were considered to be ready for extubation. The infants were changed to ETT-CPAP for a 3 minute spontaneous breathing test (SBT) before extubated. Infants were divided into two groups based upon whether they failed or passed the extubation attempt. Extubation failure was defined as reintubation within $72 \mathrm{~h}$ of extubation.

Results Forty-five of 51 infants (88\%) were successfully extubated. Out of the 51 infants only one infant failed the SBT. The three predictors of extubation success that included the SBT, ratio of minute ventilation during ETT-CPAP to mechanical ventilation and ratio of respiratory frequency during ETT-CPAP to mechanical ventilation were not significantly different. Using synchronised nasal intermittent positive pressure ventilation after extubation in the failed extubation group was significantly higher than the successful extubation group (66.7\% vs $15.7 \%$, p $=0.02$ ).

Conclusion The SBT and minute ventilation ratio in low birth weight infants were not optimal predictors of readiness for extubation. However, a further prospective study in this field with a larger number of subjects and a proper indication for extubation should be considered.

Abstract PS-379 Table 1 Clinical characteristic of the infants

\begin{tabular}{llll}
\hline & $\begin{array}{l}\text { Failed } \\
\text { extubation } \\
\text { Clinical characteristic }\end{array}$ & $\begin{array}{l}\text { Successful } \\
\text { extubation } \\
\mathbf{n}=6\end{array}$ & P value \\
\hline Gestational age (week, SD) & $29(2.4)$ & $30.5(3.6)$ & 0.31 \\
& $1,222.5$ & 1,205 & \\
Birth weight (g, IQR) & $(1,146,1,269)$ & $(1,020,1,775)$ & 0.59 \\
Male $\mathrm{n},(\%)$ & $3(50)$ & $22(48.9)$ & 1.00 \\
Vaginal delivery n, (\%) & $1(16.7)$ & $20(44.4)$ & 0.38 \\
Weight at extubation mean, g (SD) & $1,345(220.1)$ & $1,549.1 \pm 496$ & 0.99 \\
Apgar score at 5 min (median, IQR) & $8(5.8,8)$ & $8(6,8)$ & 0.48 \\
Duration of ventilation, mean (day, IQR) & $22.5(12,47)$ & $12(5,21)$ & 0.08 \\
Methylxanthine used, $\mathrm{n}(\%)$ & $4(66.7)$ & $22(48.9)$ & 0.67 \\
\hline
\end{tabular}

Abstract PS-379 Table 2 Pulmonary function test and predictive values during on continuous positive airway pressure (ETT CPAP)

\begin{tabular}{llll}
\hline & $\begin{array}{l}\text { Failed } \\
\text { extubation } \\
\text { Indicators }\end{array}$ & $\begin{array}{l}\text { Successful } \\
\text { extubation }\end{array}$ & \\
\hline ETT CPAP $\left(\mathrm{cmH}_{2} \mathrm{O}\right)$ (median, IQR) & $3(3,3)$ & $\mathbf{n}=45$ & P value \\
$\mathrm{FiO}_{2}$ & $0.3(0.21,0.3)$ & $0.3(0.21,0.3)$ & 0.71 \\
Pass Spontaneous breathing test, $\mathrm{n}(\%)$ & $6(100)$ & $44(97.8)$ & 1.00 \\
Expiratory tidal volume (ml./kg.) & & & \\
(median, IQR) & & & 0.63 \\
Expiratory minute ventilation & $5.1(3.3,6.7)$ & $6.2(4.6,7.3)$ & 0.36 \\
(l/min/kg.) (mean, SD) & $0.3(0.2)$ & $0.4(0.1)$ & 0.51 \\
Frequency (/min) (median, IQR) & $81(76.2,83.5)$ & $68(60,81)$ & 0.23 \\
Ratio $\mathrm{V}_{\mathrm{E} \text { TOT } \geq 0.8}$ & $4(66.7)$ & $41(91.1)$ & 0.14 \\
Ratio $\mathrm{V}_{\mathrm{E} \text { TOT } \geq 0.5}$ & $2(33.3)$ & $25(55.6)$ & 0.40 \\
Ratio fr $\leq 1.5$ & $1(16.7)$ & $2(4.4)$ & 0.32 \\
\hline
\end{tabular}

Ratio $V_{E}$ TOT, ratio of mean minute ventilation between breathing on ET CPAP and mechanical ventilation:

Ratio fr, ratio of mean respiratory rate between breathing on ET CPAP and mechanical ventilation. 